\title{
Marital status and its effect on lung cancer survival
}

\author{
Stacey L Tannenbaum¹, Wei Zhao ${ }^{1}$, Tulay Koru-Sengul ${ }^{1,2}$, Feng Miao ${ }^{1}$, David Lee ${ }^{1,2}$ and Margaret M Byrne ${ }^{1,2,3^{*}}$
}

\begin{abstract}
Purpose: The purpose of this study was to determine if marital status, including specific types of single status categories, is associated with length of survival in lung cancer patients.

Methods: Data from the 1996-2007 Florida Cancer Data System were linked with Agency for Health Care Administration data and U.S. Census data. Patients with both small cell and non-small cell lung cancer were identified $(n=161,228)$. Marital status was characterized by married, widowed, separated/divorced, and never married. We compared median survival time and 1, 3, and 5-year post diagnosis survival rates.
\end{abstract}

Results: Overall, 54.6\% were married, 19.1\% were widowed, 13.5\% were separated/divorced, and $12.7 \%$ had never married. Median survival in months was longest for married (9.9) and widowed (7.7) patients, and shortest for never married (4.9) and separated/divorced (4.1) patients. Five-year survival rates were 14.2\% for married, 10.7\% for widowed, $8.9 \%$ for separated/divorced, and $8.4 \%$ for never married. In univariate Cox regression, marital status was a significant predictor of better survival for married $(H R=0.70 ; p<0.001)$ and widowed $(H R=0.81 ; p<0.001)$ patients compared with never married patients, but worse for separated/divorced patients $(H R=1.03 ; p=0.003)$. Multivariate models demonstrated sustained survival benefits for married $(H R=0.86 ; p<0.001)$ and widowed $(H R=0.88 ; p<0.001)$ patients, and detriments for separated/divorced patients $(H R=1.05 ; p<0.001)$ after adjusting for extensive confounders including demographics; tumor stage, grade, and morphology; comorbidities; treatment; and smoking status.

Conclusions: Our study demonstrated that married or widowed lung cancer patients have better survival compared to patients who were never married or separated/divorced. Research to understand the mechanism of this effect, and how the beneficial effect can be extended to those who have never married or have had the marital relationship severed through divorce or separation is needed.

Keywords: Lung cancer; Marital status; Outcomes; Florida population-based cancer registry; Support system

\section{Introduction}

Lung cancer is the second most common cancer in the U.S. but is responsible for the greatest number of deaths from cancer (American Cancer Society 2013). In 2013, it is estimated that there will be 246,210 new cases and 163,890 deaths ascribed to lung cancer (Siegel et al. 2013). Estimations for 2013 are that 14\% of all incident cancers will be from lung cancer, with $28 \%$ of all cancer specific deaths in men and $26 \%$ of all deaths in women

\footnotetext{
* Correspondence: mbyrne2@med.miami.edu

'Sylvester Comprehensive Cancer Center, Miller School of Medicine, University of Miami, 1120 NW 14th Street, Miami, FL 33136, USA ${ }^{2}$ Department of Public Health Sciences, Miller School of Medicine, University of Miami, Miami, FL, USA

Full list of author information is available at the end of the article
}

being attributable to lung cancer (American Cancer Society 2013). Despite advances in chemotherapy and radiotherapy, the 5 year survival rate for all stages combined is estimated to be approximately only $16 \%$ (Siegel et al. 2013).

Because of these dismal statistics, it is important to explore all factors that might positively affect survival and mortality outcomes. Recent and growing literature suggests that psychological factors and the presence or absence of social support may be an important factor influencing the course of cancer (Ikeda et al. 2013; Pinquart \& Duberstein 2010; Cassileth et al. 1988; Rendall et al. 2011); this has been shown to be especially strong for breast cancer (Falagas et al. 2007;

\section{里 Springer}


Nausheen et al. 2009). There have been mixed results in the literature regarding the specific association of lung cancer survival and marital status. One study showed that marital status is an independent factor for predicting overall survival in both men and women (Kravdal \& Syse 2011). However another found that marriage was not significantly predictive of survival (Siddiqui et al. 2010), and others found some benefits to marriage for men (Saito-Nakaya et al. 2008). The purpose of this study was to assess, using a large comprehensive population-based dataset, whether marital status is an independent predictor of lung cancer survival.

\section{Methods}

Data

Data from two databases (1996-2007) were linked via patient ID number to form the base dataset for this study: The Florida Cancer Data System (FCDS) data and Florida's Agency for Health Care Administration (AHCA) dataset. The matches were confirmed with the patient's date of birth and gender. In addition, patients' residency was used to approximate patient level socioeconomic status (SES). From the U.S. Census, we obtained tract-level information on the percentage of households in a tract with income below the federal poverty line. Each tract was categorized as: lowest $(\geq 20 \%)$, middle-low $(\geq 10$ and $<20 \%)$, middle high ( $\geq 5$ and $<10 \%$ ), and highest $(<5 \%)$ SES based on percentage of households in the tract living in poverty. Individuals living in each tract were assigned that tract's SES level.

Diagnoses and procedure codes on all patients with lung cancer treated at Florida in- and out-patient hospitals and free-standing surgical and radiological treatment centers were obtained from the AHCA database (Agency for Healthcare Administration 2012).

The FCDS is a population-based registry mandated by law to report all cases of cancer in the state of Florida, with the exception of those diagnosed and treated by the Veterans Affairs. Approximately 95\% of all incident cases of cancer are captured. Our sample is representative of the population of lung cancer patients in Florida. As we were only interested in lung cancer, we included only those cases coded as lung cancer in the registry. From FCDS data, we captured incident cases of lung cancer, stage of disease at diagnosis and other disease characteristics, medical history, patient demographics, and methods of treatment (Florida Cancer Data System 2012).

Although we used only lung cancer cases in Florida, using FCDS data has several advantages over the main alternative, which is SEER data. First, we had the ability to link the registry data to an administrative database, AHCA data, which enabled us to enrich our control variables with information on all diagnoses and procedures. Being able to account for all comorbidities is a major strength of the study. Second, although SEER-Medicare linked data is available and would have allowed for analyses that include diagnoses, this would largely be restricted to patients 65 years and older. Our population, on the other hand, covers an age range from 18 to 110 years old. As the development of cancer in those living below the poverty line, among tobacco users, and among certain minorities commonly occurs at a younger age, a restriction to 65 years and older with the SEER-Medicare data would be much more limiting.

\section{Variables}

Overall survival, our primary endpoint, was defined as time from diagnosis to date of death or last follow-up date.

FCDS data was used to determine date of death. If FCDS did not have a date of death, FCDS and AHCA data were compared to obtain the latest date of contact. Patients without a date of death were considered to have censored data and could either be alive, or be dead and have been lost to follow up in the FCDS through moving out of the state or some other means. Our main predictor of interest was marital status which was categorized as married, widowed, separated/divorced, or never married. Following the methodology of other studies (e.g., 9,14-16), we combined separated and divorced patients into one category. In Florida, legal separation is not necessary prior to getting divorced but there are provisions of the law whereby separated partners receive the same alimony and child support payments as do divorced partners. In addition, getting divorced in Florida is easy and quick, and so divorce may be as attractive an option as separation in some cases. Therefore, those in the separated and divorced categories are likely to be more similar to each other than to other categories. Also, as the total number in the separated category was small (3.2\% of the total sample), it was not feasible to analyze them separately.

Other factors used as covariates in the regression models were added in a sequential-block stepwise fashion. Demographic characteristics included race (White, Black, Other), ethnicity (Hispanic, non-Hispanic), socioeconomic status (SES; lowest $[\geq 20 \%$ of the tract living below the federal poverty line], middle-low $[\geq 10 \%$ and $<20 \%]$, middle-high $[\geq 5 \%$ and $<10 \%]$ and, highest $[<5 \%]$ ), gender, primary payer at diagnosis (private, Medicaid, Medicare, Defense/Military/Veteran, Indian Health System, uninsured, other), smoking status (never, history, current), treatment facility characteristics (teaching, non-teaching; high volume, low volume), and geographic location (rural, urban). Clinico-pathological characteristics were tumor grade (undifferentiated, poorly-differentiated, moderatelydifferentiated, well-differentiated, other), tumor SEER summary stage (localized, regional direct extension with 
or without lymph nodes, regional lymph nodes only, distant), lymph node status (positive, negative), type of treatments (chemotherapy [yes/no], radiation [yes/no], surgery [yes/no]), and type of cancer (non-small cell, small cell). The final block of covariates added to the full model was the 31 Elixhauser comorbid conditions (yes/no) based on ICD-9 codes in the AHCA database.

\section{Population}

Our sample included all patients $\geq 18$ years diagnosed with lung cancer (1996-2007) in the state of Florida $(\mathrm{n}=179,630)$. We continued to follow this cohort for a 3-year period through 2010 to determine whether patients had died in this follow-up period. Non-Florida residents and patients with missing values for marital status, race, ethnicity, or SES were excluded $(n=18,402)$, resulting in a total sample size of 161,228.

\section{Statistical analyses}

Chi-square tests for contingency tables were used to examine the association of categorical variables. Overall median survival time and 1-, 3-, and 5-year survival rates were estimated by the Kaplan-Meier method. Logrank tests were used to compare the survival rates by marital status. Univariate and multivariate Cox proportional hazards regression models were used to obtain unadjusted and adjusted hazard ratios (HR) and 95\% confidence intervals (95\% CI). Models were adjusted by adding blocks of variables sequentially whereby model 1 was univariate with marital status as the sole explanatory variable; model 2 was multivariate adjusted for race, ethnicity, and SES; model 3 was model 2 plus all remaining demographic characteristics; model 4 was model 3 plus all clinico-pathologic characteristics; and model 5, the full model, was model 4 plus all comorbidities. Because the effect of marital status has been shown to vary by gender, we considered stratification by gender for our analyses. However, when testing for interactions between gender and marital status in the multivariate Cox regressions, no interactions were found. Therefore, gender was included as an independent predictor of survival in the models.

Patients treated in the same hospital or facility share some unmeasured characteristics that may affect clinical outcomes and therefore cannot be considered as independent observations. Thus, robust standard errors to adjust for clustering of patients within medical facilities were calculated for all models. The type-I error rate was set at 5\%. The SAS v9.3 (SAS Institute Inc., Cary, NC) was used to perform all analyses. This project was approved by the University of Miami Institutional Review Board.

\section{Results}

\section{Patient demographics and clinical variables}

Sociodemographic and clinico-pathologic characteristics of the sample are reported in Tables 1 and 2. Overall, $54.6 \%$ of the patients were married, $19.1 \%$ widowed, $13.5 \%$ separated/divorced, and $12.7 \%$ never married. The majority of the patients were male (55.7\%), White (92.5\%), non-Hispanic (93.9\%), and in the middle-high and highest SES category (54.8\%). Widowed patients were the oldest (median age 7.62 years, range 23-105) followed by married (69 years, range 20-104) and never married (65 years, range 18-102). More married and widowed patients received Medicare insurance (58.4 and $76.3 \%$, respectively) than did never married $(35.8 \%)$ or separated/divorced patients (34.6\%). Overall, $84.5 \%$ of the patients had more than 4 comorbidities; a larger proportion of married (87.6\%) and widowed (88.2\%) had more than 4 comorbidities than did never married (76.3\%) or separated/divorced (74.2\%). More married and widowed patients were diagnosed at the localized stage ( $18.3 \%$ and $18.2 \%$, respectively) than separated/ divorced (11.8\%) and never married (11.3\%). The proportion of patients with the more treatable non-small cell lung cancer was higher in married (64.5\%) and widowed (60.2\%) compared with separated/divorced (47.1\%) and never married (51.1\%).

\section{Survival}

Median survival time (MST) in months and survival rates at 1-, 3-, and 5-years post-diagnosis are displayed in Table 3 and Figure 1. Married patients had the longest MST (9.9 months), followed by widowed patients (7.7 months), while never separated/divorced patients had the shortest (4.1 months). The 1-year survival rate was longest for married (44.5\%) and widowed (38.8\%) patients, and markedly shortest for never married (31.5\% and separated/divorced patients (30.6\%). This pattern held for 3- and 5-year survival rates.

\section{Regression analysis}

Results from the 5 Cox proportional hazards regression models are shown in Table 4. In the univariate model, compared to never married, a protective effect was found for married (HR 0.70; 95\% CI=0.69-0.71) and widowed (HR 0.81; 95\% CI =0.80-0.83) patients, while separated/divorced patients had slightly worse survival (HR 1.03; 95\% CI =1.01-1.05). When the final model was adjusted for all covariates (model 5), being married (HR 0.85; 95\% CI =0.81-0.89) and widowed (HR 0.88; 95\% $\mathrm{CI}=0.84-0.93)$ remained positively associated with better survival compared with never married, and the detrimental association of separated/divorced (HR 1.05; $95 \%$ CI $=1.02-1.08$ ) with survival remained. 
Table 1 Demographic characteristics of lung cancer by marital status

\begin{tabular}{|c|c|c|c|c|c|c|c|c|c|c|}
\hline \multirow[t]{3}{*}{ Variable } & \multicolumn{2}{|c|}{ All patients } & \multicolumn{8}{|c|}{ Marital status at DX } \\
\hline & & & \multicolumn{2}{|c|}{ Never married } & \multicolumn{2}{|c|}{ Separated/Divorced } & \multicolumn{2}{|c|}{ Widowed } & \multicolumn{2}{|c|}{ Married } \\
\hline & & & $\mathrm{N}$ & $\%$ & $\mathrm{~N}$ & $\%$ & $\mathrm{~N}$ & $\%$ & $\mathrm{~N}$ & $\%$ \\
\hline All patients & 161,228 & 100.0 & 20,528 & 100.0 & 21,789 & 100.0 & 30,866 & 100.0 & 88,045 & 100.0 \\
\hline \multicolumn{11}{|l|}{ Marital status at DX } \\
\hline Never married & 20,528 & 12.7 & 20,528 & 100.0 & - & - & - & - & - & - \\
\hline Separated/Divorced & 21,789 & 13.5 & - & - & 21,789 & 100.0 & - & - & - & - \\
\hline Widowed & 30,866 & 19.1 & - & - & - & - & 30,866 & 100.0 & - & - \\
\hline Married & 88,045 & 54.6 & - & - & - & - & - & - & 88,045 & 100.0 \\
\hline \multicolumn{11}{|l|}{ Race } \\
\hline White & 149,178 & 92.5 & 17,163 & 83.6 & 19,844 & 91.1 & 28,941 & 93.8 & 83,230 & 94.5 \\
\hline Black & 10,975 & 6.8 & 3,227 & 15.7 & 1,826 & 8.4 & 1,767 & 5.7 & 4,155 & 4.7 \\
\hline Other & 1,075 & 0.7 & 138 & 0.7 & 119 & 0.5 & 158 & 0.5 & 660 & 0.7 \\
\hline \multicolumn{11}{|l|}{ Hispanic origin } \\
\hline Non-Hispanic & 151,442 & 93.9 & 18,783 & 91.5 & 20,442 & 93.8 & 29,520 & 95.6 & 82,697 & 93.9 \\
\hline Hispanic & 9,786 & 6.1 & 1,745 & 8.5 & 1,347 & 6.2 & 1,346 & 4.4 & 5,348 & 6.1 \\
\hline \multicolumn{11}{|l|}{ SES } \\
\hline Lowest & 20,668 & 12.8 & 4,674 & 22.8 & 3,723 & 17.1 & 3,755 & 12.2 & 8,516 & 9.7 \\
\hline Middle-Low & 52,264 & 32.4 & 6,912 & 33.7 & 7,818 & 35.9 & 9,999 & 32.4 & 27,535 & 31.3 \\
\hline Middle-High & 60,415 & 37.5 & 6,453 & 31.4 & 7,334 & 33.7 & 12,053 & 39.0 & 34,575 & 39.3 \\
\hline Highest & 27,881 & 17.3 & 2,489 & 12.1 & 2,914 & 13.4 & 5,059 & 16.4 & 17,419 & 19.8 \\
\hline \multicolumn{11}{|l|}{ Vital status } \\
\hline Alive & 21,919 & 13.6 & 2,376 & 11.6 & 2,332 & 10.7 & 3,685 & 11.9 & 13,526 & 15.4 \\
\hline Dead & 139,309 & 86.4 & 18,152 & 88.4 & 19,457 & 89.3 & 27,181 & 88.1 & 74,519 & 84.6 \\
\hline \multicolumn{11}{|l|}{ FCDS tobacco use } \\
\hline Never smoke & 14,001 & 8.7 & 1,409 & 6.9 & 1,068 & 4.9 & 3,683 & 11.9 & 7,841 & 8.9 \\
\hline History smoke & 64,008 & 39.7 & 5,247 & 25.6 & 5,244 & 24.1 & 13,505 & 43.8 & 40,012 & 45.4 \\
\hline Current smoke & 54,425 & 33.8 & 7,989 & 38.9 & 8,031 & 36.9 & 9,711 & 31.5 & 28,694 & 32.6 \\
\hline Unknown & 28,794 & 17.9 & 5,883 & 28.7 & 7,446 & 34.2 & 3,967 & 12.9 & 11,498 & 13.1 \\
\hline \multicolumn{11}{|l|}{ Age at diagnosis } \\
\hline Mean & \multicolumn{2}{|c|}{69.8} & \multicolumn{2}{|c|}{65.2} & \multicolumn{2}{|c|}{67.9} & \multicolumn{2}{|c|}{76.2} & \multicolumn{2}{|c|}{69.0} \\
\hline Std & \multicolumn{2}{|c|}{11.2} & \multicolumn{2}{|c|}{12.6} & & & & & & \\
\hline Median & & & & & & & & & & \\
\hline Q1 & & & & & & & & & & \\
\hline Q3 & & & & & & & & & & \\
\hline Min & & & & & & & & & & \\
\hline Max & & & & & & & & & & \\
\hline Sex & & & & & & & & & & \\
\hline Female & 71,386 & 44.3 & 7,233 & 35.2 & 11,256 & 51.7 & 22,236 & 72.0 & 30,661 & 34.8 \\
\hline Male & 89,842 & 55.7 & 13,295 & 64.8 & 10,533 & 48.3 & 8,630 & 28.0 & 57,384 & 65.2 \\
\hline Insurance status & & & & & & & & & & \\
\hline Uninsured & 5,486 & 3.4 & 1,672 & 8.1 & 1,222 & 5.6 & 426 & 1.4 & 2,166 & 2.5 \\
\hline Private insurance & 30,342 & 18.8 & 3,539 & 17.2 & 3,419 & 15.7 & 3,973 & 12.9 & 19,411 & 22.0 \\
\hline Medicaid & 5,644 & 3.5 & 1,877 & 9.1 & 1,440 & 6.6 & 529 & 1.7 & 1,798 & 2.0 \\
\hline Medicare & 89,820 & 55.7 & 7,349 & 35.8 & 7,536 & 34.6 & 23,553 & 76.3 & 51,382 & 58.4 \\
\hline
\end{tabular}


Table 1 Demographic characteristics of lung cancer by marital status (Continued)

\begin{tabular}{|c|c|c|c|c|c|c|c|c|c|c|}
\hline Defense/Military/Veteran & 2,385 & 1.5 & 341 & 1.7 & 290 & 1.3 & 233 & 0.8 & 1,521 & 1.7 \\
\hline Indian/Public & 220 & 0.1 & 65 & 0.3 & 54 & 0.2 & 31 & 0.1 & 70 & 0.1 \\
\hline Insurance, NOS & 10,491 & 6.5 & 1,232 & 6.0 & 1,210 & 5.6 & 1,040 & 3.4 & 7,009 & 8.0 \\
\hline Unknown & 16,840 & 10.4 & 4,453 & 21.7 & 6,618 & 30.4 & 1,081 & 3.5 & 4,688 & 5.3 \\
\hline \multicolumn{11}{|l|}{ Urban Rural by zip code } \\
\hline Urban & 150,025 & 93.1 & 18,998 & 92.5 & 20,259 & 93.0 & 28,966 & 93.8 & 81,802 & 92.9 \\
\hline Rural & 11,203 & 6.9 & 1,530 & 7.5 & 1,530 & 7.0 & 1,900 & 6.2 & 6,243 & 7.1 \\
\hline \multicolumn{11}{|c|}{ AAMC 2005 teaching hospital } \\
\hline Non-teaching hospital & 149,258 & 92.6 & 18,574 & 90.5 & 20,184 & 92.6 & 29,165 & 94.5 & 81,335 & 92.4 \\
\hline Teaching hospital & 11,970 & 7.4 & 1,954 & 9.5 & 1,605 & 7.4 & 1,701 & 5.5 & 6,710 & 7.6 \\
\hline \multicolumn{11}{|l|}{ Hospital volume } \\
\hline Low & 103,348 & 64.1 & 11,804 & 57.5 & 11,038 & 50.7 & 21,685 & 70.3 & 58,821 & 66.8 \\
\hline High & 57,880 & 35.9 & 8,724 & 42.5 & 10,751 & 49.3 & 9,181 & 29.7 & 29,224 & 33.2 \\
\hline
\end{tabular}

SES = Socioeconomic Status (percent living below poverty line); Lowest ( $\geq 20 \%)$; Middle-low ( $\geq 10 \%$ and $<20 \%$ ); Middle-high ( $\geq 5 \%$ and $<10 \%)$; Highest $(<5 \%)$.

\section{Discussion}

Previous research has shown an association between marital status and survival in lung cancer, and that this association may be increasing over time (Kravdal \& Syse 2011). For example, California Cancer Registry data has been used to test for overall associations of survival with marital status in lung cancer patients. This research found that for both extensive stage SCLC (HR 1.179; $\mathrm{p}<0.001)$ and NSCLC (HR 1.175; 95\% CI $=1.122$ 1.229), there are significant survival differences between unmarried and married patients ( $\mathrm{Ou}$ et al. 2008; $\mathrm{Ou}$ et al. 2009). However, there are inconsistencies in the results of studies that have explored the relative survival disadvantage of different unmarried status categories. In addition, not all studies have been able to control well for treatment and comorbidity confounding variables. Thus, the goal of this study was to explore the association of marital status with survival following a diagnosis of lung cancer using data that is representative of the Florida state population and which allows for controlling for all demographic, clinical and comorbid variables. Our main finding was that married and widowed Floridian patients with lung cancer have a survival benefit compared with those who had never married, and that separated/divorced patients had worse survival than never married patients. These findings remained significant after inclusion of all demographic, clinico-pathologic, treatment and comorbidity variables in a fully adjusted Cox regression model.

Our findings are in concordance with some, but not all of the previous literature. Similar to our findings, Manzoli et al. (Manzoli et al. 2007) found that separated/divorced cancer patients had the worst survival of any marital status group. Conversely, a number of other study have found that never-married patients have worse survival than both widowed and separated/ divorced patients (Pinquart \& Duberstein 2010; Kravdal \& Syse 2011; Kravdal 2013; Kravdal 2001), at least for some categories of patients. Early data from Norway (women diagnosed with cancer between 1996 and 1990 (Kvikstad et al. 1995)) showed that divorced women had an overall increased hazard ratio of 1.17 (95\% CI $=1.07-1.27)$ for cancers including lung cancer compared to married women, whereas widows had no increased risk. However, in 2001, Kravdal (Kravdal 2001) found that for Norwegian women with lung cancer, being widowed was associated with the worst survival outcomes (HR 1.19; 95\% CI = 1.09-1.30) compared with married women. The same study showed that, for male lung cancer patients, never married status was associated with the worst outcomes (HR 1.23; 95\% CI $=1.16-1.30$ ), whereas widowhood was associated with only half that detrimental effect (HR 1.12; $95 \% \mathrm{CI}=1.10-1.20)$. In the most recent data from Norway, a status of never married was found to be worst for both men and women with lung cancer, but the order of the relationship of widowed and divorced/separated status to survival was different for men and women (Kravdal 2013).

Other studies have divided divorced and separated individuals into discrete categories. One such study found that separated status carried the worst survival outcomes for 5-year and 10-year relative survival for cancer patients - approximately $72 \%$ and $64 \%$ the survival time of married patients (Sprehn et al. 2009). Another study (Lai et al. 1999), which explored SEER data for each cancer type separately, found the relative risk scores (compared to married) to be 1.18 for single, 1.16 for separated, 1.13 for divorced, and 1.08 for widowed male lung cancer patients (all significant differences); but no significant difference among relative risk scores for females.

Although many studies have found differences, albeit in inconsistent ways, among the different categories of 
Table 2 Pathological and clinical characteristics

\begin{tabular}{|c|c|c|c|c|c|c|c|c|c|c|}
\hline \multirow[t]{3}{*}{ Variable } & \multirow{2}{*}{\multicolumn{2}{|c|}{ All patients }} & \multicolumn{8}{|c|}{ Marital status at DX } \\
\hline & & & \multicolumn{2}{|c|}{ Never married } & \multicolumn{2}{|c|}{ Separated/Divorced } & \multicolumn{2}{|c|}{ Widowed } & \multicolumn{2}{|c|}{ Married } \\
\hline & $\mathrm{N}$ & $\%$ & $\mathrm{~N}$ & $\%$ & $\mathrm{~N}$ & $\%$ & $\mathrm{~N}$ & $\%$ & $\mathrm{~N}$ & $\%$ \\
\hline All & 161,228 & 100.0 & 20,528 & 100.0 & 21,789 & 100.0 & 30,866 & 100.0 & 88,045 & 100.0 \\
\hline \multicolumn{11}{|l|}{ Co-morbidity } \\
\hline None & 12,754 & 7.9 & 2,978 & 14.5 & 3,509 & 16.1 & 1,516 & 4.9 & 4,751 & 5.4 \\
\hline $1 \sim 2$ & 3,793 & 2.4 & 667 & 3.2 & 761 & 3.5 & 583 & 1.9 & 1,782 & 2.0 \\
\hline $3 \sim 4$ & 8,477 & 5.3 & 1,216 & 5.9 & 1,348 & 6.2 & 1,544 & 5.0 & 4,369 & 5.0 \\
\hline$>4$ & 136,204 & 84.5 & 15,667 & 76.3 & 16,171 & 74.2 & 27,223 & 88.2 & 77,143 & 87.6 \\
\hline \multicolumn{11}{|l|}{ SEER stage } \\
\hline Localized & 26,672 & 16.5 & 2,316 & 11.3 & 2,572 & 11.8 & 5,632 & 18.2 & 16,152 & 18.3 \\
\hline Regional, direct extension \pm lymph nodes & 19,478 & 12.1 & 2,184 & 10.6 & 2,153 & 9.9 & 3,765 & 12.2 & 11,376 & 12.9 \\
\hline Regional, lymph nodes only & 13,820 & 8.6 & 1,371 & 6.7 & 1,486 & 6.8 & 2,697 & 8.7 & 8,266 & 9.4 \\
\hline Distant & 64,374 & 39.9 & 8,049 & 39.2 & 7,415 & 34.0 & 12,571 & 40.7 & 36,339 & 41.3 \\
\hline Unknown/Unstaged & 36,884 & 22.9 & 6,608 & 32.2 & 8,163 & 37.5 & 6,201 & 20.1 & 15,912 & 18.1 \\
\hline \multicolumn{11}{|l|}{ Types of lung cancer } \\
\hline $\mathrm{SCLC}$ & 20,073 & 12.5 & 2,250 & 11.0 & 2,358 & 10.8 & 4,012 & 13.0 & 11,453 & 13.0 \\
\hline NSCLC & 96,134 & 59.6 & 10,493 & 51.1 & 10,270 & 47.1 & 18,589 & 60.2 & 56,782 & 64.5 \\
\hline Other & 45,021 & 27.9 & 7,785 & 37.9 & 9,161 & 42.0 & 8,265 & 26.8 & 19,810 & 22.5 \\
\hline \multicolumn{11}{|l|}{ Grade } \\
\hline Undifferentiated & 11,780 & 7.3 & 1,264 & 6.2 & 1,399 & 6.4 & 2,292 & 7.4 & 6,825 & 7.8 \\
\hline Poorly-differentiated & 37,134 & 23.0 & 4,161 & 20.3 & 4,049 & 18.6 & 6,745 & 21.9 & 22,179 & 25.2 \\
\hline Moderately-differentiated & 18,492 & 11.5 & 1,808 & 8.8 & 1,897 & 8.7 & 3,492 & 11.3 & 11,295 & 12.8 \\
\hline Well-differentiated & 5,654 & 3.5 & 507 & 2.5 & 535 & 2.5 & 1,188 & 3.8 & 3,424 & 3.9 \\
\hline Unknown/not stated & 88,168 & 54.7 & 12,788 & 62.3 & 13,909 & 63.8 & 17,149 & 55.6 & 44,322 & 50.3 \\
\hline \multicolumn{11}{|l|}{ Regional nodes positive } \\
\hline No & 19,699 & 12.2 & 1,737 & 8.5 & 2,066 & 9.5 & 3,358 & 10.9 & 12,538 & 14.2 \\
\hline Yes & 11,604 & 7.2 & 1,105 & 5.4 & 1,271 & 5.8 & 1,770 & 5.7 & 7,458 & 8.5 \\
\hline Unknown & 129,925 & 80.6 & 17,686 & 86.2 & 18,452 & 84.7 & 25,738 & 83.4 & 68,049 & 77.3 \\
\hline \multicolumn{11}{|l|}{ Chemotherapy } \\
\hline No & 93,242 & 57.8 & 10,371 & 50.5 & 9,716 & 44.6 & 22,128 & 71.7 & 51,027 & 58.0 \\
\hline Yes & 51,037 & 31.7 & 5,855 & 28.5 & 5,933 & 27.2 & 7,395 & 24.0 & 31,854 & 36.2 \\
\hline Unknown & 16,949 & 10.5 & 4,302 & 21.0 & 6,140 & 28.2 & 1,343 & 4.4 & 5,164 & 5.9 \\
\hline \multicolumn{11}{|l|}{ Radiation Therapy } \\
\hline No & 46,765 & 29.0 & 5,948 & 29.0 & 5,054 & 23.2 & 12,691 & 41.1 & 23,072 & 26.2 \\
\hline Yes & 102,232 & 63.4 & 10,955 & 53.4 & 11,154 & 51.2 & 17,615 & 57.1 & 62,508 & 71.0 \\
\hline Unknown & 12,231 & 7.6 & 3,625 & 17.7 & 5,581 & 25.6 & 560 & 1.8 & 2,465 & 2.8 \\
\hline \multicolumn{11}{|l|}{ Surgery } \\
\hline No & 114,045 & 70.7 & 13,607 & 66.3 & 12,571 & 57.7 & 24,659 & 79.9 & 63,208 & 71.8 \\
\hline Yes & 34,896 & 21.6 & 3,144 & 15.3 & 3,534 & 16.2 & 5,794 & 18.8 & 22,424 & 25.5 \\
\hline Unknown & 12,287 & 7.6 & 3,777 & 18.4 & 5,684 & 26.1 & 413 & 1.3 & 2,413 & 2.7 \\
\hline
\end{tabular}

SES = Socioeconomic Status (percent living below poverty line); Lowest ( $\geq 20 \%)$; Middle-low ( $\geq 10 \%$ and $<20 \%) ;$ Middle-high ( $\geq 5 \%$ and $<10 \%)$; Highest $(<5 \%)$.

unmarried individuals, this is not true for across the board. A review of the effect of marriage on survival broadly (Rendall et al. 2011) found little or no differences between never married, separated/divorced, and widowed statuses. A study of lung cancer in Japan found no significant increased risk of death in widowed female lung 
Table 3 Median survival time and survival rates, $n=161,228$

\begin{tabular}{|c|c|c|c|c|}
\hline & \multirow[t]{2}{*}{$\begin{array}{c}\text { Median } \\
\text { survival (months) }\end{array}$} & \multicolumn{3}{|c|}{$\begin{array}{l}\text { Survival rates (\%) at time } \\
\text { (yrs) after diagnosis }\end{array}$} \\
\hline & & $1 \mathrm{yr}$ & 3 yrs & 5 yrs \\
\hline Overall & 8.1 & 39.9 & 18.2 & 12.1 \\
\hline \multicolumn{5}{|l|}{ Marital status } \\
\hline Never married & 4.9 & 31.5 & 13.0 & 8.4 \\
\hline Separated/Divorced & 4.1 & 30.6 & 13.5 & 8.9 \\
\hline Widowed & 7.7 & 38.8 & 17.2 & 10.7 \\
\hline Married & 9.9 & 44.5 & 20.9 & 14.2 \\
\hline \multicolumn{5}{|l|}{ Race } \\
\hline White & 8.1 & 40.1 & 18.5 & 12.3 \\
\hline Black & 7.0 & 36.2 & 14.5 & 8.9 \\
\hline Other & 10.2 & 46.2 & 20.1 & 12.5 \\
\hline \multicolumn{5}{|l|}{ Hispanic origin } \\
\hline No & 8.0 & 39.8 & 18.2 & 12.1 \\
\hline Yes & 8.4 & 40.5 & 17.9 & 12.1 \\
\hline \multicolumn{5}{|l|}{ SES } \\
\hline Lowest & 6.5 & 34.8 & 13.8 & 8.7 \\
\hline Middle-Low & 7.6 & 38.3 & 16.8 & 11.0 \\
\hline Middle-High & 8.5 & 41.1 & 19.4 & 12.8 \\
\hline Highest & 9.5 & 44.0 & 21.7 & 15.1 \\
\hline
\end{tabular}

SES = Socioeconomic Status (percent living below poverty line); Lowest ( $\geq 20 \%$ ); Middle-low ( $\geq 10 \%$ and $<20 \%$ ); Middle-high ( $\geq 5 \%$ and $<10 \%$ ); Highest $(<5 \%)$. cancer patients compared to married patients, and no significant increased risk of death for separated/divorced male or female patients compared to married patients although widowed males patients had increased risk of death (HR 1.7; 95\% CI =1.2-2.5) (Saito-Nakaya et al. 2008).

One way that our results differ from much of the previous findings in the literature e.g., (Kravdal \& Syse 2011; Saito-Nakaya et al. 2008; Kravdal 2013; Lai et al. 1999) is that we did not find differences between men and women in the relationship between marital status and survival. As gender and marital status interaction term in our Cox regression was not significant, indicating that marital status has the same modifying effect on survival in both genders, although gender does have a significant direct effect on survival, with males having worse survival then females with lung cancer (results not shown). The reason for this difference in our population from previous findings is unclear.

Our findings and these others suggest that some aspect of marriage and social networks in general seem to afford patients a comparatively longer time before succumbing to a disease. Previous studies on marriage and survival focused on the social support benefits that married couples have compared with never married or divorced/separated. For example, Pinquart (Pinquart \& Duberstein 2010) posited that social networks, which would include marriage, would have effects on: biological pathways (neuroendocrine or neuro-immune pathways), health behaviors, access to health care systems and assistance with navigating its complexities, the likelihood of receiving

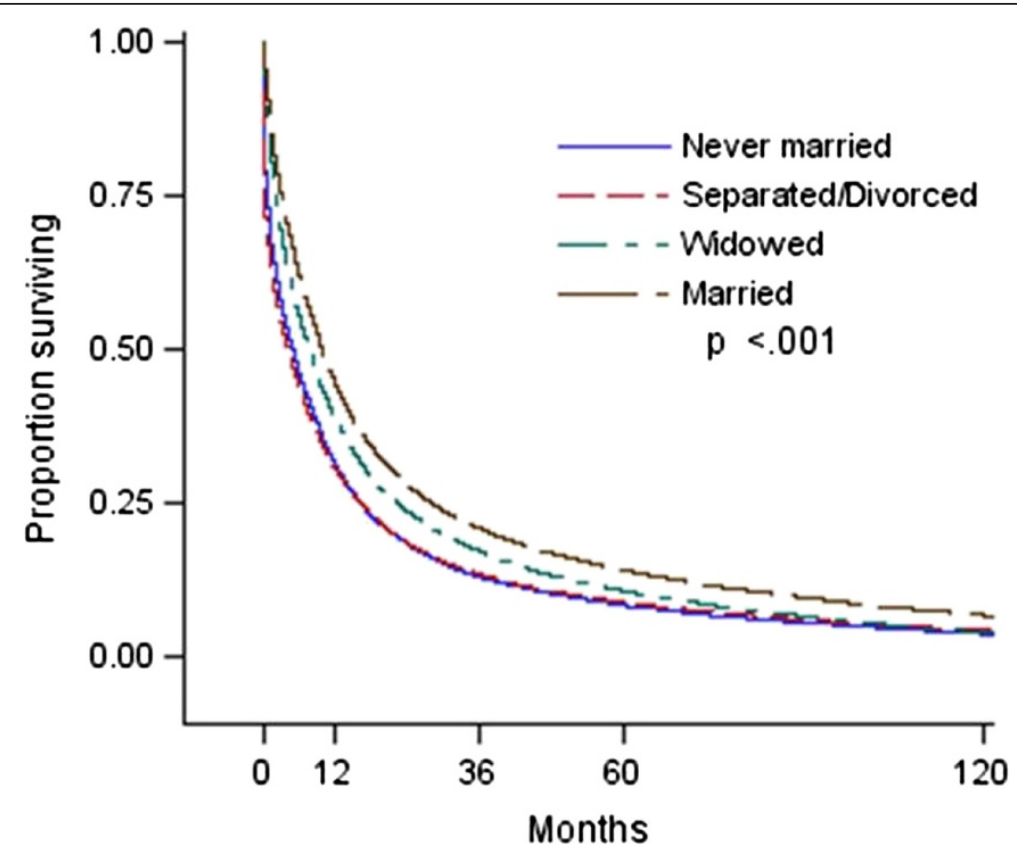

Figure 1 This figure illustrates proportion surviving by marital status. 
Table 4 Proportional cox regression models, $n=161,228$

\begin{tabular}{|c|c|c|c|c|c|c|c|c|c|c|c|}
\hline \multirow[b]{2}{*}{ Prognostic factors } & \multirow[b]{2}{*}{ Category } & \multicolumn{2}{|l|}{ Model 1} & \multicolumn{2}{|l|}{ Model 2} & \multicolumn{2}{|l|}{ Model 3} & \multicolumn{2}{|l|}{ Model 4} & \multicolumn{2}{|l|}{ Model 5} \\
\hline & & HR $(95 \% \mathrm{Cl})$ & $P$ value & HR $(95 \% \mathrm{Cl})$ & $P$ value & HR $(95 \% \mathrm{Cl})$ & $P$ value & $\mathrm{HR}(95 \% \mathrm{Cl})$ & $P$ value & HR $(95 \% \mathrm{Cl})$ & $P$ value \\
\hline \multirow[t]{4}{*}{ Marital status } & Never married & 1.00 & & 1.00 & & 1.00 & & 1.00 & & 1.00 & \\
\hline & Separated/ Divorced & $1.03(1.01,1.05)$ & 0.003 & $1.03(0.89,1.20)$ & 0.654 & $1.03(0.96,1.10)$ & 0.461 & $1.04(1.01,1.07)$ & 0.008 & $1.05(1.02,1.08)$ & $<.001$ \\
\hline & Widowed & $0.81(0.80,0.83)$ & $<.001$ & $0.82(0.59,1.14)$ & 0.240 & $0.77(0.63,0.94)$ & 0.010 & $0.87(0.82,0.91)$ & $<.001$ & $0.88(0.84,0.93)$ & $<.001$ \\
\hline & Married & $0.70(0.69,0.71)$ & $<.001$ & $0.71(0.53,0.95)$ & 0.021 & $0.70(0.60,0.83)$ & $<.001$ & $0.82(0.78,0.87)$ & $<.001$ & $0.85(0.81,0.89)$ & $<.001$ \\
\hline \multirow[t]{3}{*}{ Race } & White & 1.00 & & 1.00 & & 1.00 & & 1.00 & & 1.00 & \\
\hline & Black & $1.12(1.10,1.14)$ & $<.001$ & $0.97(0.88,1.05)$ & 0.438 & $1.04(1.01,1.07)$ & 0.021 & $0.99(0.95,1.02)$ & 0.472 & $0.99(0.95,1.02)$ & 0.391 \\
\hline & Other & $0.91(0.85,0.97)$ & 0.005 & $0.91(0.85,0.97)$ & 0.007 & $1.00(0.93,1.08)$ & 0.944 & $0.96(0.89,1.04)$ & 0.314 & $0.85(0.78,0.93)$ & $<.001$ \\
\hline \multirow[t]{2}{*}{ Hispanic origin } & Non-Hispanic & 1.00 & & 1.00 & & 1.00 & & 1.00 & & 1.00 & \\
\hline & Hispanic & $0.98(0.96,1.01)$ & 0.148 & $0.93(0.85,1.02)$ & 0.130 & $0.97(0.90,1.06)$ & 0.499 & $0.94(0.89,0.99)$ & 0.026 & $0.91(0.86,0.96)$ & $<.001$ \\
\hline \multirow[t]{4}{*}{ SES } & Lowest & 1.00 & & 1.00 & & 1.00 & & 1.00 & & 1.00 & \\
\hline & Middle-Low & $0.90(0.89,0.92)$ & $<.001$ & $0.93(0.90,0.97)$ & $<.001$ & $0.95(0.92,0.98)$ & $<.001$ & $0.96(0.93,0.98)$ & 0.002 & $0.96(0.94,0.99)$ & 0.005 \\
\hline & Middle-High & $0.84(0.83,0.85)$ & $<.001$ & $0.88(0.84,0.93)$ & $<.001$ & $0.90(0.86,0.93)$ & $<.001$ & $0.92(0.89,0.95)$ & $<.001$ & $0.92(0.90,0.95)$ & $<.001$ \\
\hline & Highest & $0.77(0.76,0.79)$ & $<.001$ & $0.82(0.77,0.88)$ & $<.001$ & $0.85(0.80,0.91)$ & $<.001$ & $0.88(0.85,0.92)$ & $<.001$ & $0.89(0.85,0.92)$ & $<.001$ \\
\hline
\end{tabular}

Model 1: Univariate.

Model 2: Multivariate only with Marital status + Race/Ethnicity/SES.

Model 3: Multivariate - Marital status + Race/Ethnicity/SES + demographics.

Model 4: Multivariate - Marital status + Race/Ethnicity/SES + demographics + clinical.

Model 5: Multivariate - Marital status + Race/Ethnicity/SES + demographics + clinical + individual comorbidities.

Notes: there is no interaction between marital status and race, ethnicity and SES respectively.

SES = Socioeconomic Status (percent living below poverty line); Lowest $(\geq 20 \%)$; Middle-low ( $\geq 10 \%$ and $<20 \%$ ); Middle-high ( $>5 \%$ and $<10 \%)$; Highest $(<5 \%)$. 
vigorous and aggressive, active cancer treatment, and psychological consequences. All of these could have direct and/or indirect effects on survival. Empirically, Luszczynska, et al. (Luszczynska et al. 2012) found that patients with perceived/received family support had improved psychological and physical quality of life. Stressrelated psychosocial factors have been shown to have a deleterious effect on survival in patients with lung cancer (Chida et al. 2008). Taniguchi et al. (Taniguchi et al. 2003) found that men who were not married had more psychological distress than married men (Umberson 1992). Lastly, married couples have been shown to engage in healthier lifestyle behaviors and less risky behaviors compared with unmarried couples (Krieger 1992).

This study had some limitations. It was a cross-sectional study so causality could not be assessed. However, as this was a linkage of databases some of the information was collected at a later time period. The databases that we have access to do not have individual-level indicators of SES; therefore, we used neighborhood-level poverty as a proxy. However, using neighborhood indicators of SES has been shown to be a valid and reliable methodology (29). Also, marital status was determined only at the time of diagnosis and patients' status may have changed over time.

Our study showing marital status is a strong independent predictor of survival was unique in that we had a linkage of two large databases: 1) the FCDS registry containing incident cancer cases plus other demographic information and 2) AHCA database, providing codes for diagnoses and procedures received as the patient went forward with treatments for a large age range of patients (18-110 years). In addition, we had valid proxy of individual SES information utilizing information from the U.S. Census. With this information we were able to control for demographic and clinico-pathological characteristics, (i.e., tumor characteristics, hospital type, treatments) as well as comprehensive comorbidities.

\section{Conclusions}

We found strong evidence that married and widowed patients with lung cancer fare better in terms of survival than those who never married even after adjusting for some extensive factors including some associated with social support, whereas divorced/separated patients did worse. This suggests that some other factor(s) associated with marriage - even after the marriage has ended through widowhood, but not divorce or separation- are associated with survival. Further research to fully understand these factors and how the beneficial effect can be extended to those who have never been married or have had marriage terminated through separation or divorce is needed.

\section{Competing interests}

The authors declare that they have no competing interests.

\section{Authors' contributions}

SLT, WZ, TKS, FM, DL, and MB made substantial contributions to conception and design, and acquisition of data, and analysis and interpretation of data; SLT, WZ, TKS, FM, DL, and MB have been involved in drafting the manuscript or revising it critically for important intellectual content; and SLT, WZ, TKS, $\mathrm{FM}, \mathrm{DL}$, and MB have given final approval of the version to be published.

\section{Acknowledgments}

Funding for this study was provided by James \& Esther King Florida Biomedical Research Program (Grant 10KG-06).

\section{Author details}

${ }^{1}$ Sylvester Comprehensive Cancer Center, Miller School of Medicine, University of Miami, 1120 NW 14th Street, Miami, FL 33136, USA.

${ }^{2}$ Department of Public Health Sciences, Miller School of Medicine, University of Miami, Miami, FL, USA. ${ }^{3}$ Department of Surgery, Miller School of Medicine, University of Miami, Miami, FL, USA.

Received: 8 May 2013 Accepted: 25 September 2013

Published: 3 October 2013

\section{References}

Agency for Healthcare Administration (2012). Available at: http://ahca.myflorida. com/index.shtml. Accessed April 2013

American Cancer Society (2013) Lung Cancer (non-small cell). http://www.cancer.org/ cancer/lungcancer-non-smallcell/detailedguide/non-small-cell-lung-cancer-keystatistics. Accessed 04/09/2013

Cassileth BR, Walsh WP, Lusk EJ (1988) Psychosocial correlates of cancer survival: a subsequent report 3 to 8 years after cancer diagnosis. J Clin Oncol 6(11):1753-1759

Chida Y, Hamer M, Wardle J, Steptoe A (2008) Do stress-related psychosocial factors contribute to cancer incidence and survival? Nat Clin Prac Oncol 5(8):466-475.

Falagas ME, Zarkadoulia EA, loannidou EN, Peppas G, Christodoulou C, Rafailidis PI (2007) The effect of psychosocial factors on breast cancer outcome: a systematic review. Breast Cancer Res 9(4):R44. doi:10.1186/bcr1744

Florida Cancer Data System (2012) Florida's Statewide Population-Based Cancer Registry. Available at: http://fcds.med.miami.edu/welcome.html. Accessed April 2013

Ikeda A, Kawachi I, Iso H, Iwasaki M, Inoue M, Tsugane S (2013) Social support and cancer incidence and mortality: the JPHC study cohort II. Cancer Causes Control. doi:10.1007/s10552-013-0147-7

Kravdal O (2001) The impact of marital status on cancer survival. Soc Sci Med 52(3):357-368

Kravdal O (2013) The poorer cancer survival among the unmarried in Norway: Is much explained by comorbidities? Soc Sci Med 81:42-52. doi:10.1016/ j.socscimed.2013.01.012

Kravdal H, Syse A (2011) Changes over time in the effect of marital status on cancer survival. BMC Public Health 11:804

Krieger N (1992) Overcoming the absence of socioeconomic data in medical records: validation and application of a census-based methodology. Am J Public Health 82(5):703-710

Kvikstad A, Vatten LJ, Tretli S (1995) Widowhood and divorce in relation to overall survival among middle-aged Norwegian women with cancer. Br J Cancer 71:1343-1347

Lai H, Lai S, Krongrad A, Trapido E, Page JB, McCoy CB (1999) The effect of marital status on survival in late-stage cancer patients: An analysis based on Surveillance, Epidemiology, and End Results (SEER) data, in the United States. Int J Behav Med 6(2):150-176

Luszczynska A, Pawlowska I, Cieslak R, Knoll N, Scholz U (2012) Social support and quality of life among lung cancer patients: a systematic review. Psychooncology. doi:10.1002/pon.3218

Manzoli L, Villari P, Pirone G, Boccia A (2007) Marital status and mortality in the elderly: a systematic review and meta-analysis. Soc Sci Med 64:77-94

Nausheen B, Gidron Y, Peveler R, Moss-Morris R (2009) Social support and cancer progression: a systematic review. J Psychosom Res 67(5):403-415. doi:10.1016/j.jpsychores.2008.12.012 
Ou S-HI, Zell JA, Ziogas A, Anton-Culver H (2008) Low socioeconomic status is a poor prognostic factor for survival in stage I nonsmall cell lung cancer and is independent of surgical treatment, race, and marital status. Cancer 112:2011-2020. doi:10.1002/cncr.23397

Ou S-HI, Ziogas A, Zell JA (2009) Prognostic factors for survival in extensive stage small cell lung cancer (ED-SCLC): Importance of smoking history, socioeconomic and marital statuses, and ethnicity. J Thorac Oncol 4(1):37-43

Pinquart M, Duberstein PR (2010) Associations of social networks with cancer mortality: a meta-analysis. Crit Rev Oncol Hematol 75(2):122-137. doi:10.1016/j.critrevonc.2009.06.003

Rendall MS, Weden MM, Favreault MM, Waldron H (2011) The protective effect of marriage for survival: a review and update. Demography 48(2):481-506. doi:10.1007/s13524-011-0032-5

Saito-Nakaya K, Nakaya N, Akechi T, Inagaki M, Asai M, Goto K, Nagai K, Nishiwaki Y, Tsugane S, Fukudo S, Uchitomi Y (2008) Marital status and non-small cell lung cancer survival: the Lung Cancer Database Project in Japan. Psycho-oncology 17(9):869-876. doi:10.1002/pon.1296

Siddiqui F, Bae K, Langer CJ, Coyne JC, Gamerman V, Komaki R, Choy H, Curran WJ, Watkins-Bruner D, Movsas B (2010) The influence of gender, race, and marital status on survival in lung cancer patients: analysis of Radiation Therapy Oncology Group trials. J Thorac Oncol 5(5):631-639

Siegel R, Naishadham D, Jemal A (2013) Cancer statistics, 2013. CA Cancer J Clin 63(1):11-30. doi:10.3322/caac.21166

Sprehn GC, Chambers JE, Saykin AJ, Konski A, Johnstone PA (2009) Decreased cancer survival in individuals separated at time of diagnosis: critical period for cancer pathophysiology? Cancer 115(21):5108-5116. doi:10.1002/cncr.24547

Taniguchi K, Akechi T, Suzuki S, Mihara M, Uchitomi Y (2003) Lack of marital support and poor psychological responses in male cancer patients. Support Care Cancer 11(9):604-610. doi:10.1007/s00520-003-0495-z

Umberson D (1992) Gender, marital status and the social control of health behavior. Soc Sci Med 34(8):907-917

doi:10.1186/2193-1801-2-504

Cite this article as: Tannenbaum et al: Marital status and its effect on lung cancer survival. SpringerPlus 2013 2:504.

\section{Submit your manuscript to a SpringerOpen ${ }^{\circ}$ journal and benefit from:}

- Convenient online submission

- Rigorous peer review

- Immediate publication on acceptance

- Open access: articles freely available online

- High visibility within the field

- Retaining the copyright to your article

Submit your next manuscript at $>$ springeropen.com 